\title{
Emerging Pathogenic Unit of Vesicle-Cloaked Murine Norovirus Clusters is Resistant to Environmental Stresses and $\mathbf{U V}_{254}$ Disinfection
}

\section{Supporting Information}

Mengyang Zhang, ${ }^{1,2}$ Sourish Ghosh, ${ }^{2}$ Manish Kumar, ${ }^{2}$ Marianita Santiana, ${ }^{2}$ Christopher K.E. Bleck, ${ }^{3}$ Natthawan Chaimongkol, ${ }^{4}$ Nihal Altan-Bonnet, ${ }^{2 *}$ Danmeng Shuai ${ }^{1 *}$

${ }^{1}$ Department of Civil and Environmental Engineering, The George Washington University, Washington, DC 20052, United States

${ }^{2}$ Laboratory of Host-Pathogen Dynamics, National Heart Lung and Blood Institute, National Institutes of Health, Bethesda, MD 20892, United States

${ }^{3}$ Electron Microcopy Core, National Heart Lung and Blood Institute, National Institutes of Health, Bethesda, MD 20892, United States

${ }^{4}$ Laboratory of Infectious Diseases, National Institute of Allergy and Infectious Diseases, National Institutes of Health, Bethesda, MD 20892, United States

* Corresponding Author:

Nihal Altan-Bonnet, Phone: 301-435-0817 Email: nihal.altan-bonnet@nih.gov, Website: https://www.nhlbi.nih.gov/science/host-pathogen-dynamics Danmeng Shuai, Phone: 202-994-0506, Fax: 202-994-0127, Email: danmengshuai@gwu.edu, Website: http://materwatersus.weebly.com

Environmental Science and Technology

7 Tables, 12 Figures, and 16 Pages 


\section{Isolation of MNV-1 vesicles using MagCapture Exosome Isolation Kit PS}

For each preparation, $60 \mu \mathrm{L}$ of streptavidin magnetic beads was incubated with $10 \mu \mathrm{L}$ of biotinlabelled exosome capture solution on a rotator at $4{ }^{\circ} \mathrm{C}$ for $10 \mathrm{~min}$. After incubation, the TIM4 coated magnetic beads were washed three times and were then ready to use. Concentrated vesicle solution prepared by resuspending the vesicle pellet was incubated with the TIM4 coated magnetic beads on the rotator at $4{ }^{\circ} \mathrm{C}$ for at least $3 \mathrm{~h}$ or overnight, with the presence of an exosome binding enhancer (the enhancer to the sample ratio was 1:500 by volume). Beads bound with viral vesicles were collected and washed. MNV-1 vesicles were eluted with a pre-warmed elution buffer $(>25$ $\mu \mathrm{l})$ at $37{ }^{\circ} \mathrm{C}$ for $5 \mathrm{~min}$. The TIM4 coated magnetic beads were reused for one more time and incubated with the concentrated vesicle solution after the first round of viral vesicle separation. Again, the bound MNV-1 vesicles were eluted, and they were combined with the vesicles harvested in the first-round of separation. The same TIM4 coated magnetic beads were reused for only once to guarantee their desired binding efficiency to the viral vesicles. Purified MNV-1 vesicles were stored at $4{ }^{\circ} \mathrm{C}$ until further use.

\section{Transmission electron microscopy (TEM) of viral vesicles}

The morphology of $\mathrm{UV}_{254}$-treated and untreated MNV-1 vesicles was compared using TEM images captured by a JEM 1200EX (JEOL USA) microscope equipped with an XR611 camera under the voltage of $80 \mathrm{keV}$. Samples were negative stained before proceeding to the microscopic analysis by following the protocol described in Santiana et al., with modification. ${ }^{1}$ Samples were firstly mounted on the glow discharged carbon coated copper grids (CF400-Cu, Electron Microscopy Sciences) and incubated at the room temperature for $30 \mathrm{~min}$. After being fixed by $1 \%$ glutaraldehyde, fixative residual was rinsed out by two times of phosphate-buffered saline (PBS) and once of $\mathrm{ddH}_{2} \mathrm{O}$. Finally, samples were stained by a pre-made negative stain NanoVan ${ }^{\mathrm{TM}}$ 
(Nanoprobes Inc., 14701). Stained samples were dried and stored at the room temperature until ready for imaging.

\section{Vesicle-cloaked rotavirus clusters were persistent in raw wastewater.}

Vesicle-cloaked rotavirus clusters (also known as rotavirus vesicles) were isolated from the stool of mouse pups (BALB/cJ, The Jackson Laboratory, 5-day-old) infected by Epizootic Diarrhea of Infant Mice (EDIM) rotavirus using TIM4 coated magnetic beads, as described in the manuscript. The stool was firstly suspended in PBS and centrifuged for multiple cycles (from 500 $\times \mathrm{g}$ to $5,000 \times \mathrm{g}$ ) to remove large particles prior to the magnetic-bead-based harvesting and purification. Raw wastewater was collected from a local municipal wastewater reclamation facility (VA) and filtered through a $0.22 \mu \mathrm{m}$ membrane before experiments to exclude the bacteria. Purified rotavirus vesicles were incubated with the filtered raw wastewater at room temperature in the dark for 1, 3, and 7 days, respectively. After incubation, rotavirus vesicles were re-isolated from the wastewater by the TIM4 coated magnetic beads and proceeded to sodium dodecyl

sulphate-polyacrylamide gel electrophoresis (SDS-PAGE)/Western blot for measuring the level of VP6, a capsid protein of rotavirus. The Western blot image is shown in Figure S12a, and the corresponding quantification is shown in Figure S12b.

SDS-PAGE was carried out with gradient 4-20\% TGX precast gels (BioRad, CA) at $250 \mathrm{~V}$ and transferred to a $0.2 \mu \mathrm{m}$ nitrocellulose membrane in a Trans-Blot Turbo transfer system. The membrane was blocked with $5 \%$ of fat free milk in $1 \mathrm{X}$ tris-buffered saline-Tween 20 (TBST) buffer for $1 \mathrm{~h}$ at the room temperature before incubated with a primary antibody at $4{ }^{\circ} \mathrm{C}$ overnight. The primary antibody was washed off by $1 \mathrm{X}$ TBST buffer for 5 times and $10 \mathrm{~min}$ each time. The membrane was then incubated with a secondary antibody for $1 \mathrm{~h}$ at the room temperature following 5 times of wash with $1 \mathrm{X}$ TBST buffer. Finally, the membrane was treated with Lumigen ECL Plus 
and developed using the Amersham Imager 600 (GE Healthcare Life Sciences, PA). The primary antibody was using guinea pig polyclonal anti-RVVP6 dissolving in 1X TBS containing 1\% bovine serum albumin (BSA), $0.02 \% \mathrm{NaN}_{3}$, and $0.1 \%$ Tween $20 .{ }^{1}$ The secondary antibody was using mouse anti-guinea pig dissolving in blocking buffer. ${ }^{1}$

Results clearly indicated that the rotavirus vesicles remained intact for up to 3 days in the filtered raw wastewater. By incubation of 7 days in the filtered raw wastewater, $\sim 60 \%$ of rotavirus vesicles could still be recovered by the TIM4 coated magnetic beads. It was the first time for evaluating the persistence of viral vesicles in wastewater, and the results highlight that the viral vesicles were highly persistent and could participate in long-term transmission in an aquatic environment. 
Table S1. Calibration of $U_{254}$ exposure in disinfection.

\begin{tabular}{|c|c|c|c|c|c|c|c|}
\hline \multicolumn{8}{|c|}{ MNV-1 vesicles } \\
\hline $\begin{array}{c}\mathrm{UV}_{254} \text { dose between } \\
\text { sampling intervals } \\
\left(\mathrm{mJ} \mathrm{cm}^{-2}\right)\end{array}$ & 0 & 5 & 5 & 10 & 10 & 10 & 10 \\
\hline Solution height (mm) & 7.34 & 6.29 & 5.25 & 4.20 & 3.15 & 2.10 & 1.05 \\
\hline ABS & \multicolumn{7}{|c|}{0.016} \\
\hline $\log _{10}\left(\mathrm{I}_{0} / \mathrm{I}\right)$ & $1.2 \times 10^{-2}$ & $1.0 \times 10^{-2}$ & $8.0 \times 10^{-3}$ & $7.0 \times 10^{-3}$ & $5.0 \times 10^{-3}$ & $3.0 \times 10^{-3}$ & $2.0 \times 10^{-3}$ \\
\hline $\begin{array}{c}\text { Cumulative } U_{254} \\
\text { dose after calibration } \\
\left(\mathrm{mJ} \mathrm{cm}^{-2}\right)\end{array}$ & 0 & 4.9 & 9.8 & 20 & 30 & 39 & 49 \\
\hline \multicolumn{8}{|c|}{ Free MNV-1 } \\
\hline $\begin{array}{c}\mathrm{UV}_{254} \text { dose between } \\
\text { sampling intervals } \\
\left(\mathrm{mJ} \mathrm{cm}^{-2}\right)\end{array}$ & 0 & 5 & 5 & 10 & 10 & 10 & 10 \\
\hline Solution height $(\mathrm{mm})$ & 7.34 & 6.29 & 5.25 & 4.20 & 3.15 & 2.10 & 1.05 \\
\hline ABS & \multicolumn{7}{|c|}{0.15} \\
\hline $\log _{10}\left(\mathrm{I}_{0} / \mathrm{I}\right)$ & $1.1 \times 10^{-1}$ & $9.1 \times 10^{-2}$ & $7.6 \times 10^{-2}$ & $6.1 \times 10^{-2}$ & $4.6 \times 10^{-2}$ & $3.0 \times 10^{-2}$ & $1.5 \times 10^{-2}$ \\
\hline $\begin{array}{c}\text { Cumulative } \mathrm{UV}_{254} \\
\text { dose after calibration } \\
\left(\mathrm{mJ} \mathrm{cm}^{-2}\right)\end{array}$ & 0 & 4.1 & 8.3 & 17 & 26 & 35 & 45 \\
\hline
\end{tabular}

Table S2. Sequence information used in RT-qPCR.

\begin{tabular}{|c|c|c|c|c|}
\hline Name & Sequence & $\begin{array}{c}\text { Starting } \\
\text { Position }\end{array}$ & $\begin{array}{c}\text { Ending } \\
\text { Position }\end{array}$ & $\begin{array}{c}\text { Product } \\
\text { Length } \\
\text { (bases) }\end{array}$ \\
\hline $\begin{array}{c}\text { Forward } \\
\text { primer } \\
\text { MNV-1 }\end{array}$ & 5'-GGCTACGGCTGGACATGTCT-3' & 292 & 311 & \\
\hline $\begin{array}{c}\text { Reverse } \\
\text { primer } \\
\text { MNV-1 }\end{array}$ & 5'-GCGTCAGGCCTATCCTCCTT-3' & 370 & 351 & \\
\hline $\begin{array}{c}\text { Probe } \\
\text { MNV-1 } \\
\text { (6-FAM- } \\
\text { BHQ1- } \\
\text { labeled })\end{array}$ & 5'-CTATCTTCCGCCGTTACCCCCATCTG-3' & 319 & 344 & 79 \\
\hline $\begin{array}{c}\text { cDNA } \\
\text { standard } \\
\text { MNV-1 }\end{array}$ & $\begin{array}{l}\text { 5'-TCTGATCCGTGGCTACGGCTGGACATGTCTG } \\
\text { GGCCTAAGGAGGATAGGCCTGACGCGCCCTCC } \\
\text { CATG-3' }\end{array}$ & 282 & 381 & \\
\hline
\end{tabular}


Table S3. Summary of qPCR assay efficiencies and $\mathrm{R}^{2}$ of standard curve regression. Ranges are reported for all the plates ran for the project.

\begin{tabular}{|c|c|c|}
\hline Assay Target & Efficiency Range (\%) & R $^{\mathbf{2}}$ Range \\
\hline MNV-1 & $90.8-106.3$ & $0.998-1$ \\
\hline
\end{tabular}

Table S4. RT-qPCR quantification of undiluted and diluted extracted viral RNA $(n=3)$.

\begin{tabular}{|c|c|c|c|}
\hline $\begin{array}{l}\text { Sample dilution } \\
\text { factor }\end{array}$ & $\begin{array}{c}\text { Average RNA } \\
\text { concentration } \\
\text { (gene copies } \mathrm{mL}^{-1} \text { ) }\end{array}$ & $\begin{array}{l}\text { Standard deviation of } \\
\text { RNA concentration } \\
\text { (gene copies } \mathrm{mL}^{-1} \text { ) }\end{array}$ & $\begin{array}{c}\text { Estimated RNA } \\
\text { concentration before } \\
\text { dilution } \\
\text { (gene copies } \mathrm{mL}^{-1} \text { ) }\end{array}$ \\
\hline $1: 1$ & $3.49 \times 10^{6}$ & $6.93 \times 10^{4}$ & $3.49 \pm 0.07 \times 10^{6}$ \\
\hline $1: 2$ & $1.99 \times 10^{6}$ & $9.58 \times 10^{4}$ & $3.97 \pm 0.19 \times 10^{6}$ \\
\hline $1: 5$ & $7.64 \times 10^{5}$ & $2.81 \times 10^{4}$ & $3.82 \pm 0.14 \times 10^{6}$ \\
\hline $1: 10$ & $4.31 \times 10^{5}$ & $3.12 \times 10^{4}$ & $4.31 \pm 0.31 \times 10^{6}$ \\
\hline $1: 20$ & $1.89 \times 10^{5}$ & $6.28 \times 10^{3}$ & $3.78 \pm 0.13 \times 10^{6}$ \\
\hline
\end{tabular}

Table S5. Summary of particle size and concentration of MNV-1 vesicles after multiple cycles of freeze-thaw. The average size of viral vesicles is given as average \pm standard deviation $(\mathrm{n}=5)$.

\begin{tabular}{|c|c|c|c|c|c|c|}
\hline \multirow{2}{*}{$\begin{array}{c}\text { Freezing and } \\
\text { thawing cycles }\end{array}$} & \multicolumn{4}{|c|}{ Size Distribution (nm) } & \multicolumn{2}{c|}{ Concentration (particles $\mathrm{mL}^{-1}$ ) } \\
\cline { 2 - 7 } & Average size & D10 & D50 & D90 & Average & Standard Error \\
\hline 0 & $184.9 \pm 64.7$ & 127.1 & 169.3 & 260.8 & $5.62 \times 10^{8}$ & $5.45 \times 10^{7}$ \\
\hline 10 & $186.8 \pm 63.1$ & 128.5 & 170.0 & 264.7 & $4.47 \times 10^{8}$ & $2.89 \times 10^{7}$ \\
\hline 20 & $188.5 \pm 63.7$ & 129.2 & 171.6 & 271.1 & $4.45 \times 10^{8}$ & $2.30 \times 10^{7}$ \\
\hline
\end{tabular}


Table S6. Summary of particle size and concentration of MNV-1 vesicles after treatment with detergents and a non-detergent lysis buffer. The average size of viral vesicles is given as average \pm standard deviation $(n=5)$. Statistical significance was compared to the MNV-1 vesicles without treatment $\left({ }^{*} \mathrm{p}<0.05\right)$.

\begin{tabular}{|c|c|c|c|c|c|c|}
\hline \multirow{2}{*}{ Sample } & \multicolumn{3}{|c|}{ Size Distribution(nm) } & \multicolumn{2}{c|}{ Concentration (particles $\left.\mathrm{mL}^{-1}\right)$} \\
\cline { 2 - 7 } & $\begin{array}{c}\text { Average } \\
\text { size }\end{array}$ & D10 & D50 & D90 & Average & Standard Error \\
\hline Untreated vesicles & $182.0 \pm 64.0$ & 125.6 & 167.9 & 253.3 & $1.07 \times 10^{9}$ & $1.14 \times 10^{8}$ \\
\hline $\begin{array}{c}\text { Vesicles lysis by the non- } \\
\text { detergent lysis buffer }\end{array}$ & $169.1 \pm 46.3$ & 126.5 & $158.2^{*}$ & $220.5^{*}$ & $3.10 \times 10^{8 *}$ & $1.96 \times 10^{7}$ \\
\hline Vesicles lysis by NP-40 & $142.6 \pm 40.7$ & $90.2^{*}$ & $144.1 *$ & $181.3^{*}$ & $4.23 \times 10^{8 *}$ & $1.32 \times 10^{7}$ \\
\hline Vesicles lysis by SDS & $155.1 \pm 51.4$ & $114.2^{*}$ & $142.5^{*}$ & $205.9^{*}$ & $1.52 \times 10^{8 *}$ & $6.24 \times 10^{6}$ \\
\hline
\end{tabular}

Table S7. Summary of particle size and concentration of MNV-1 vesicles after $\mathrm{UV}_{254}$ irradiation. The size of viral vesicles is given as average \pm standard deviation $(n=4)$.

\begin{tabular}{|c|c|c|c|c|c|c|}
\hline \multirow{2}{*}{$\begin{array}{c}\mathrm{UV}_{254} \text { dose } \\
\left(\mathrm{mJ} \mathrm{cm} \mathrm{cm}^{-2}\right.\end{array}$} & \multicolumn{4}{|c|}{ Size Distribution $(\mathrm{nm})$} & \multicolumn{2}{c|}{ Concentration $\left(\right.$ particles $\left.\mathrm{mL}^{-1}\right)$} \\
\cline { 2 - 7 } & $\begin{array}{c}\text { Average } \\
\text { size }\end{array}$ & $\mathrm{D} 10$ & $\mathrm{D} 50$ & $\mathrm{D} 90$ & Average & Standard Error \\
\hline 0 & $161.2 \pm 44.6$ & 126.5 & 151.4 & 207.3 & $5.10 \times 10^{7}$ & $2.75 \times 10^{6}$ \\
\hline 25 & $156.5 \pm 38.1$ & 122.6 & 149.4 & 200.4 & $5.33 \times 10^{7}$ & $5.69 \times 10^{6}$ \\
\hline 40 & $155.6 \pm 46.3$ & 121.6 & 146.8 & 191.2 & $4.79 \times 10^{7}$ & $5.97 \times 10^{6}$ \\
\hline
\end{tabular}




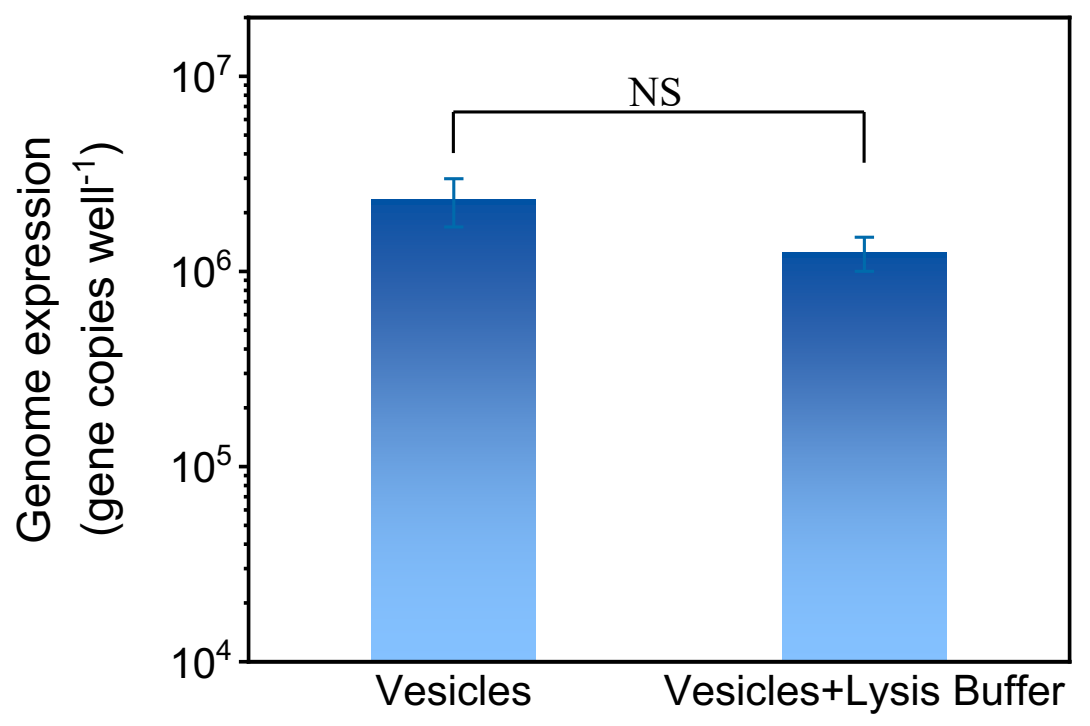

Figure S1. Non-detergent lysis buffer did not influence the infectivity of MNV-1. $\mathrm{n}=6$, and error bars represent standard deviations. NS $\mathrm{p}>0.05$.

Instead of using non-detergent lysis buffer A and B sequentially for breaking up the vesicles, the control experiment (i.e., Vesicles+Lysis Buffer) was conducted by neutralizing buffer A by buffer B before adding to MNV-1 vesicles and infecting RAW 264.7 cells. In this control experiment, the solution contained intact MNV-1 vesicles and all chemical components from the non-detergent lysis buffer. By evaluating the infectivity of viral vesicles (i.e., Vesicles) and Vesicles + Lysis Buffer, we found that the chemicals in the non-detergent lysis buffer did not inhibit virus propagation and infectivity. 


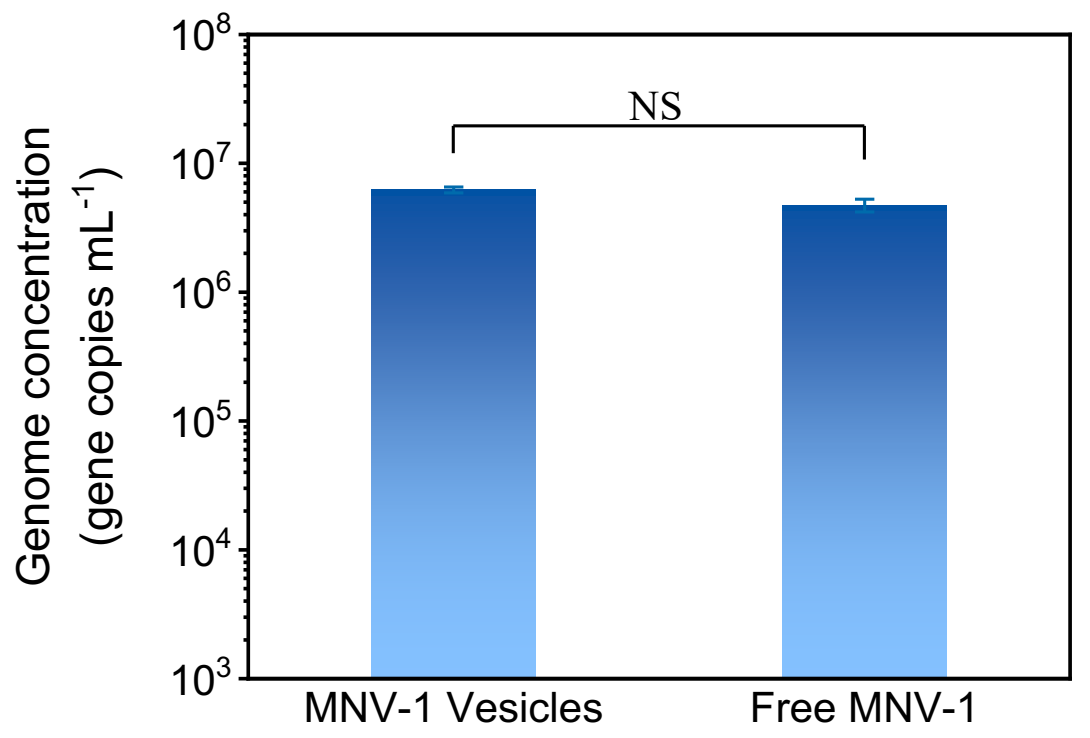

Figure S2. Genome concentration of MNV-1 vesicles and free MNV-1 lysed from the same batch and the same amount of vesicles. MNV-1 vesicles were divided into two equal fractions with one fraction left intact and the other fraction lysed with the non-detergent buffer (Detergent-Free Exosomal Protein Extraction Kit, 101Bio, P201) to release free MNV-1 particles. Since lysis buffer addition increased the volume of free MNV-1, an equal volume of PBS was amended to the MNV-1 vesicles to compensate the volume increase in free MNV-1. RT-qPCR was used for quantification. $\mathrm{n}=4$, and error bars represent standard deviations. NS $\mathrm{p}>0.05$. 


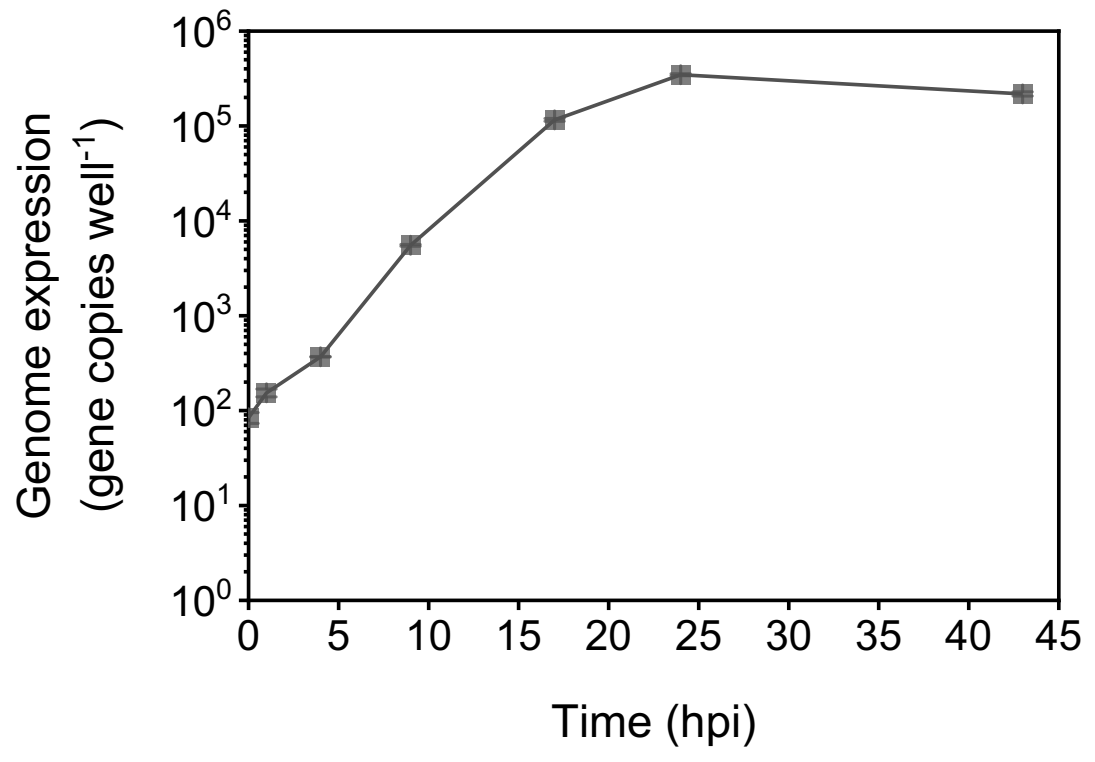

Figure S3. Growth curve of MNV-1 vesicles in RAW 264.7 cells without inoculum removal. $n=$ 4, and error bars represent standard deviations. hpi is hours post-infection.

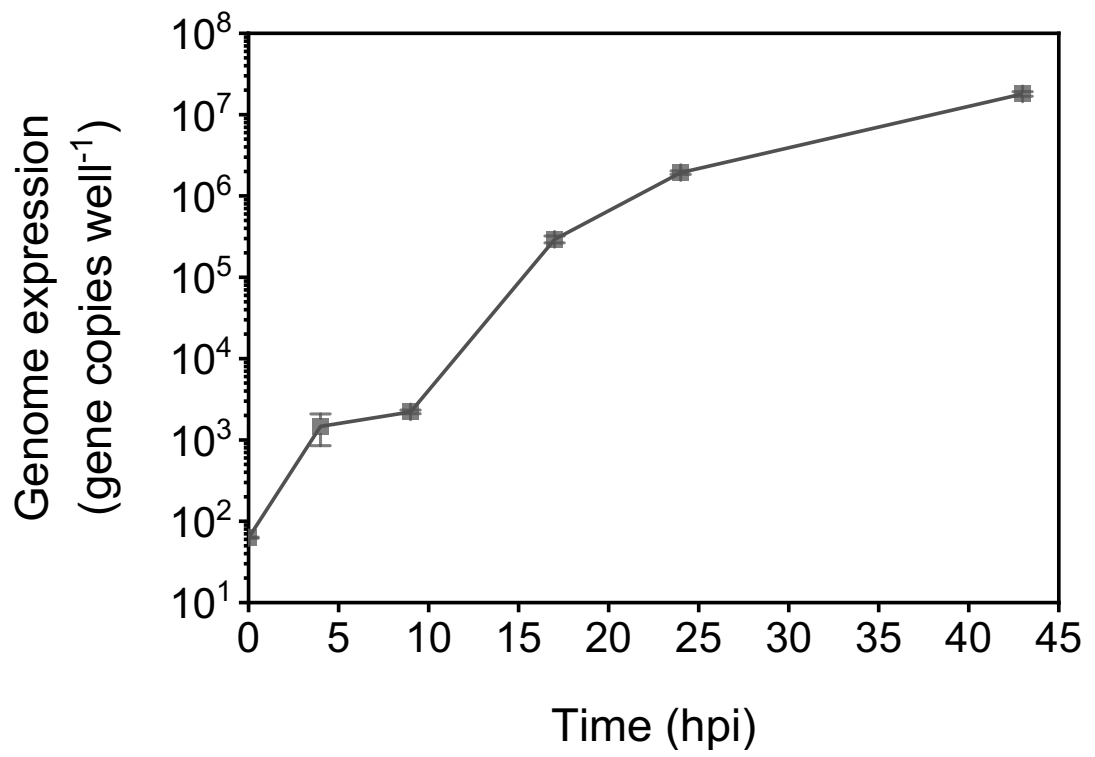

Figure S4. Growth curve of MNV-1 vesicles in RAW 264.7 cells, and the inoculum was removed after 4 hpi and replenished with the serum free media. $n=4$, and error bars represent standard deviations. hpi is hours post-infection. 


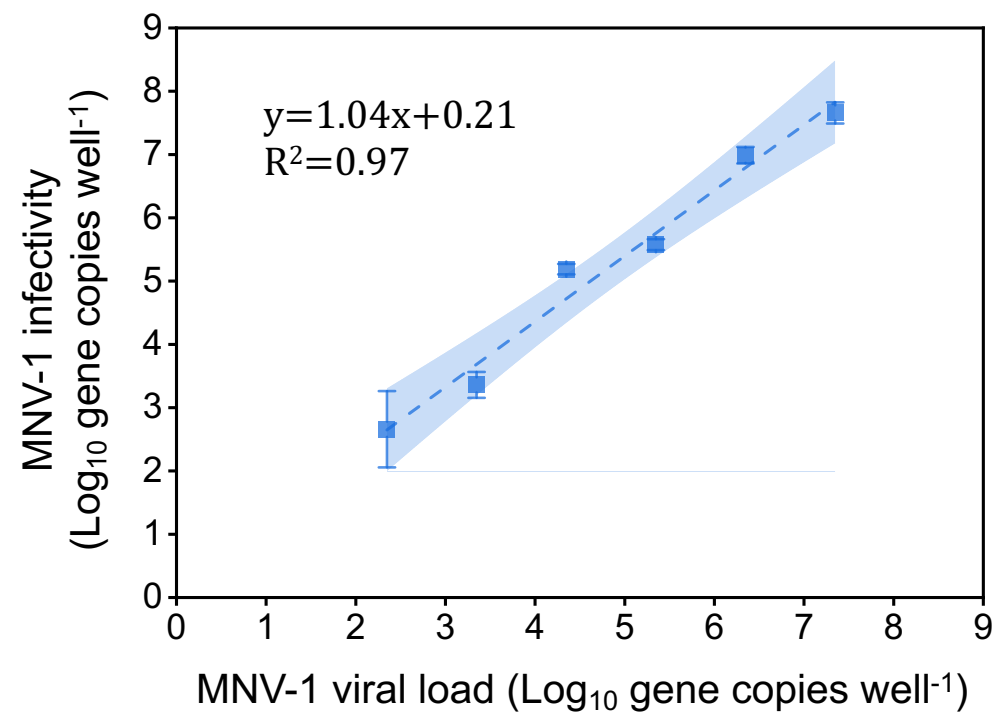

Figure S5. Linear correlation of the infectivity of MNV-1 stock with the viral load before infection. The viral load of genome input was determined by RT-qPCR, and the infectivity was determined by ICC-RT-qPCR after 24 hours of cell culture. Serial dilutions of MNV-1 stock were used for infection. $\mathrm{n}=4$, error bars represent standard deviations, and the light blue region highlights $95 \%$ of confidence intervals of linear regression. 


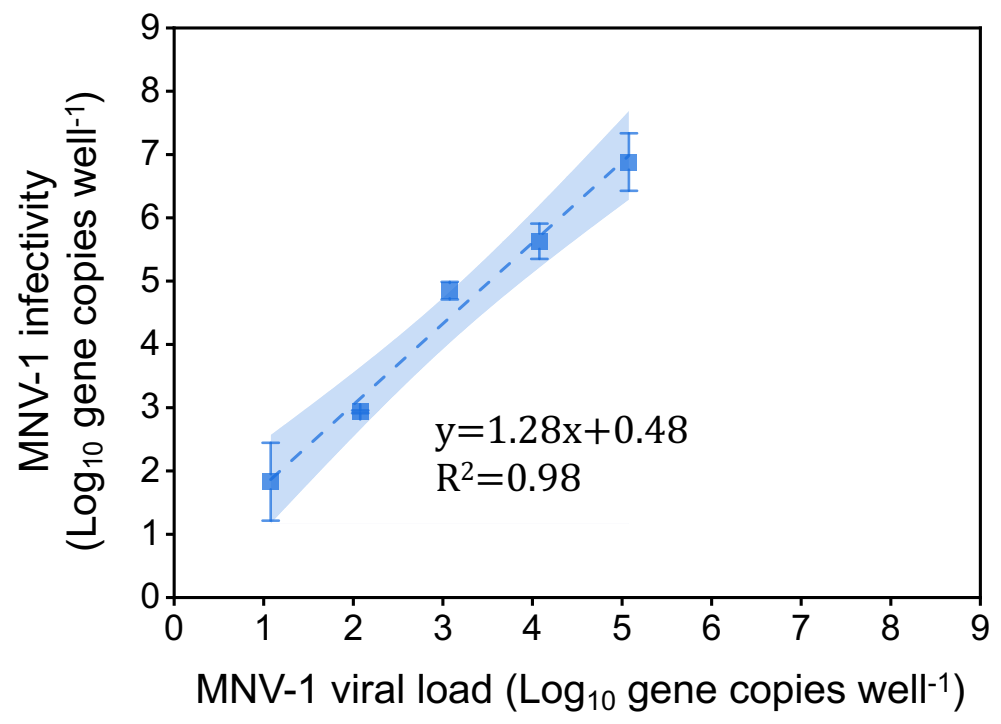

Figure S6. Linear correlation of the infectivity of MNV-1 vesicles with the viral load before infection. The viral load of genome input was determined by RT-qPCR, and the infectivity was determined by ICC-RT-qPCR after 24 hours of cell culture. Serial dilutions of MNV-1 vesicles were used for infection. $\mathrm{n}=4$, error bars represent standard deviations, and the light blue region highlights $95 \%$ of confidence intervals of linear regression. 


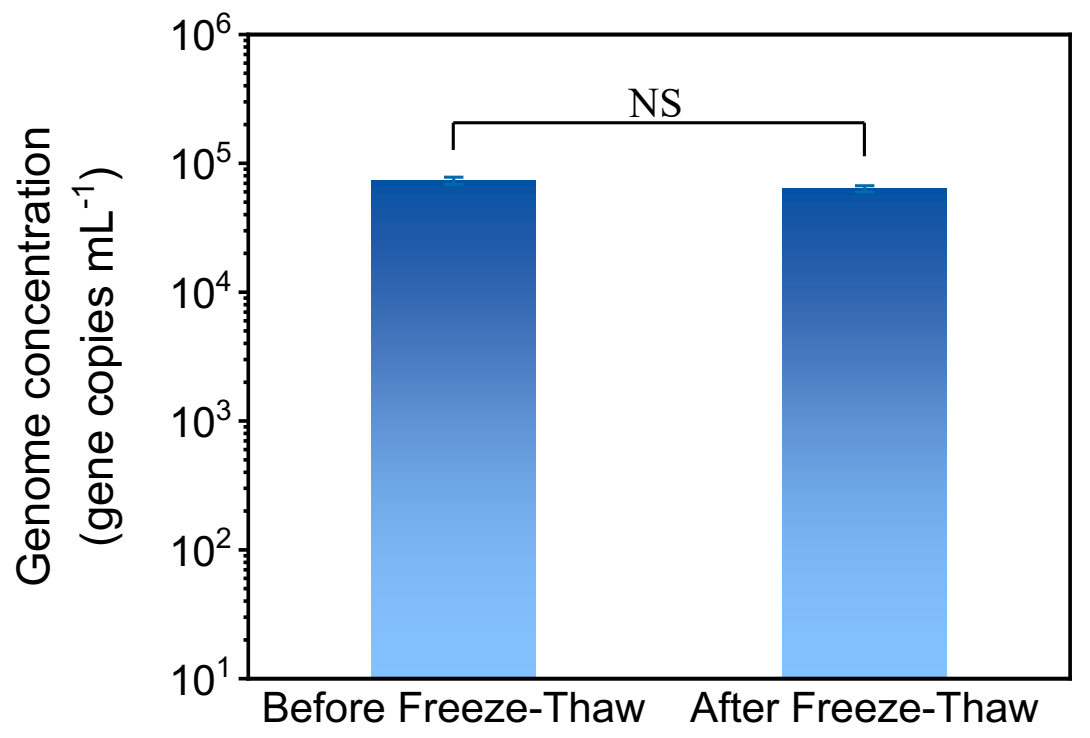

Figure S7. Recovery of MNV-1 vesicles before and after 20 cycles of freeze-thaw. MNV-1 vesicles were recovered by the TIM4 coated magnetic beads in the MagCapture Exosome Isolation Kit PS (FUJIFILM Wako Pure Chemical, 293-77601) and quantified by RT-qPCR. $\mathrm{n}=4$, and error bars represent standard deviations. NS $\mathrm{p}>0.05$. 


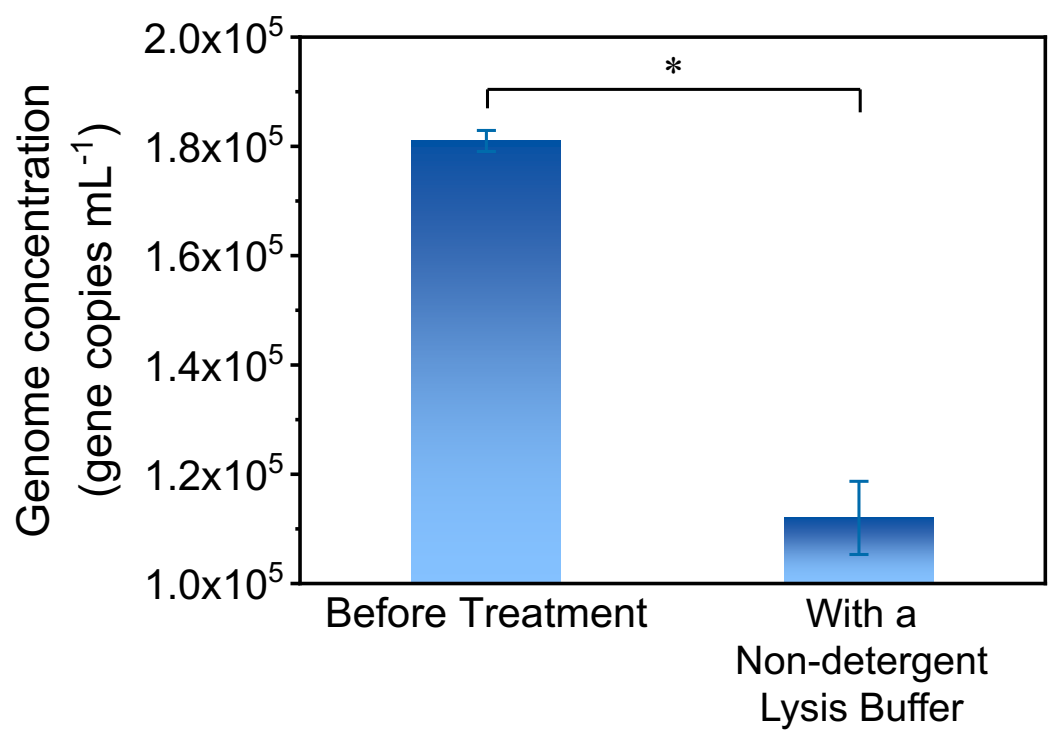

Figure S8. Recovery of MNV-1 vesicles before and after treatment by a non-detergent lysis buffer (Detergent-Free Exosomal Protein Extraction Kit, 101Bio, P201). MNV-1 vesicles were recovered by the TIM4 coated magnetic beads in the MagCapture Exosome Isolation Kit PS (FUJIFILM Wako Pure Chemical, 293-77601) and quantified by RT-qPCR. $n=4$, and error bars represent standard deviations. ${ }^{*} \mathrm{p}<0.05$.
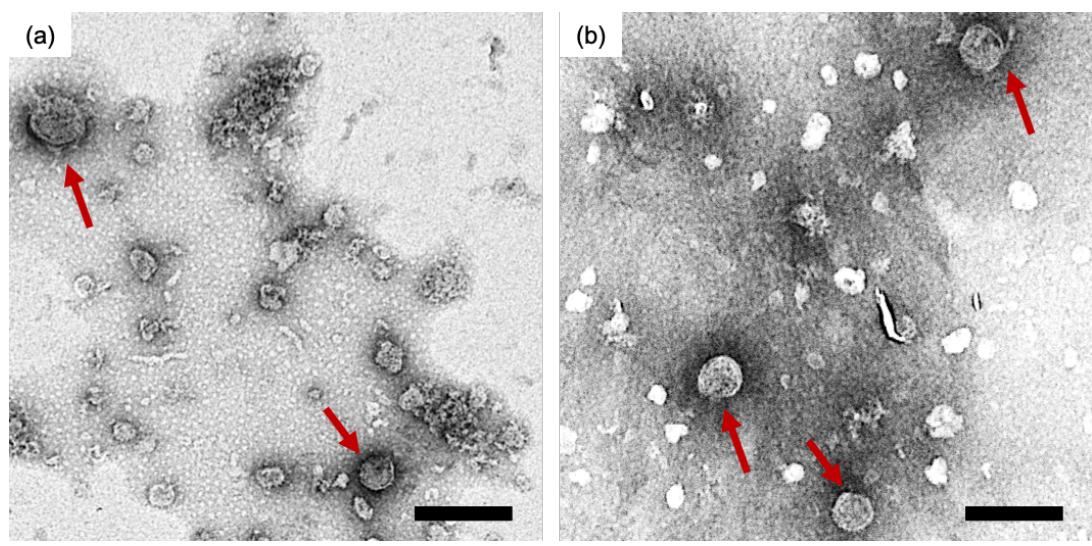

Figure S9. Characterizations of vesicle-cloaked MNV-1 clusters (a) before and (b) after exposure to $40 \mathrm{~mJ} \mathrm{~cm}^{-2}$ of $\mathrm{UV}_{254}$ by TEM. MNV-1 vesicles are highlighted with red arrows. Scale bars are $200 \mathrm{~nm}$. 


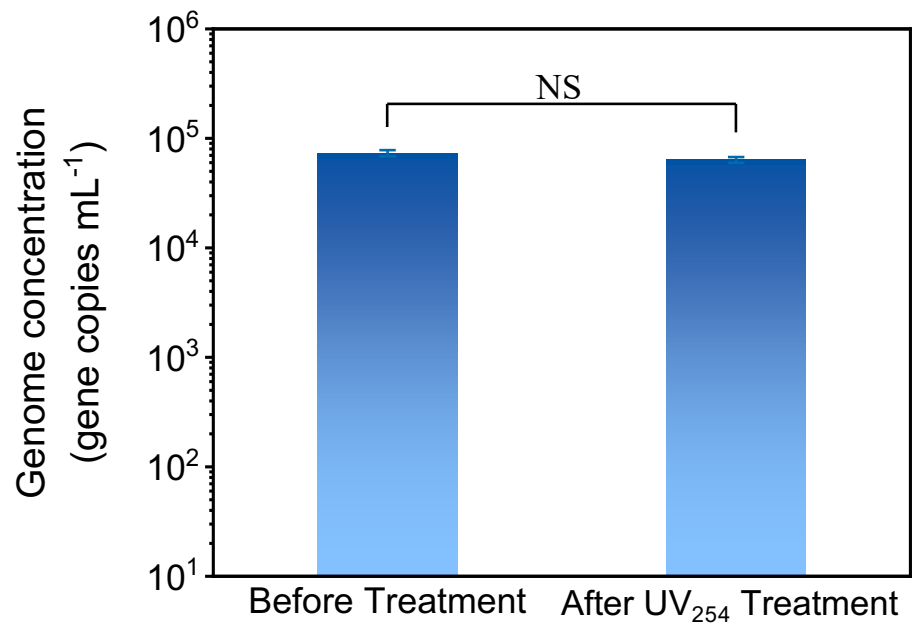

Figure S10. Recovery of MNV-1 vesicles before and after exposure to $40 \mathrm{~mJ} \mathrm{~cm}^{-2}$ of $\mathrm{UV}_{254}$. MNV1 vesicles were recovered by the TIM4 coated magnetic beads in the MagCapture Exosome Isolation Kit PS (FUJIFILM Wako Pure Chemical, 293-77601) and quantified by RT-qPCR. $\mathrm{n}=$ 4, and error bars represent standard deviations. NS $\mathrm{p}>0.05$.

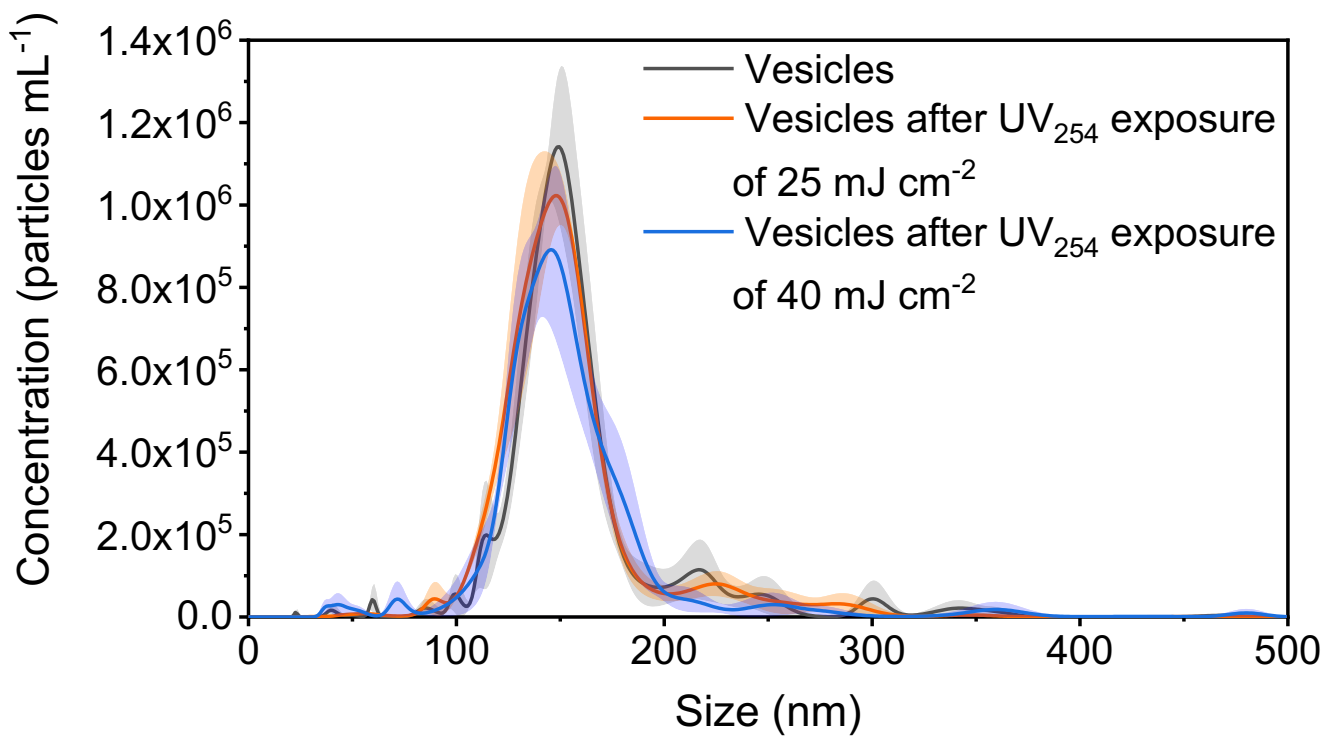

Figure S11. Hydrodynamic size distribution of MNV-1 vesicles before and after $\mathrm{UV}_{254}$ disinfection. Error bars represent standard errors for four replicates. 
(a)

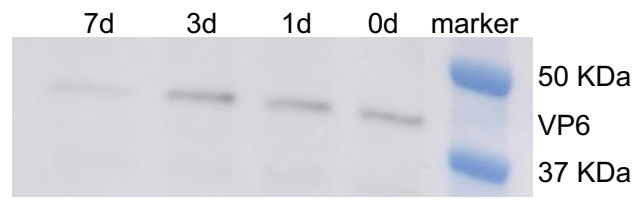

(b)

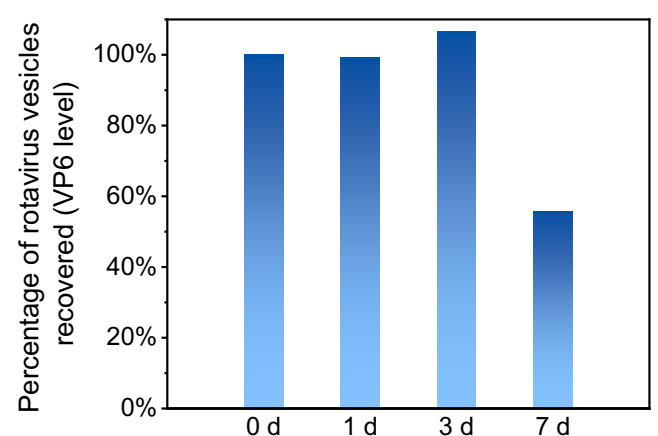

Figure S12. (a) Western blot for rotavirus vesicles after incubation with filtered raw wastewater

for $0,1,3$, and 7 days, respectively. (b) Quantification of VP6 protein levels of rotavirus by Western blot. Rotavirus vesicles were purified from mouse stool.

\section{Reference}

1. Santiana, M.; Ghosh, S.; Ho, B. A.; Rajasekaran, V.; Du, W. L.; Mutsafi, Y.; De JesusDiaz, D. A.; Sosnovtsev, S. V.; Levenson, E. A.; Parra, G. I.; Takvorian, P. M.; Cali, A.; Bleck, C.; Vlasova, A. N.; Saif, L. J.; Patton, J. T.; Lopalco, P.; Corcelli, A.; Green, K. Y.; Altan-Bonnet, N., Vesicle-Cloaked Virus Clusters Are Optimal Units for Inter-organismal Viral Transmission. Cell Host Microbe 2018, 24, (2), 208-220 e8. 